\title{
Challenges for Protection of Future HVDC Grids
}

\author{
María José Pérez-Molina*, D. Marene Larruskain, Pablo Eguía López and \\ Garikoitz Buigues
}

Department of Electrical Engineering, University of the Basque Country, Universidad del País Vasco, Euskal Herriko Unibertsitatea, Bilbao, Spain

Nowadays, High Voltage Direct Current (HVDC) transmissions are gaining relevance in long distance and renewable energy integration projects over the conventional Alternating Current (AC) transmissions due to several advantages as improved flexibility and independent active and reactive power controllability. Despite that, the high currents and voltage collapses generated by fault conditions in HVDC systems imply some unresolved technical challenges regarding the detection, location and clearance of faults. Faults have to be cleared in a very short time range in order to minimize their impact on the system. For this objective, very fast protection algorithms and reliable HVDC circuit breakers are required. This paper focuses on the technical challenges and limitations of HVDC protection systems. This way, protection requirements and different types of measurement devices are considered. Protection algorithms are classified into local-measurement-based and communication-based, highlighting the most important characteristics. In addition, the different technologies of HVDC circuit breakers are compared. Finally, the characteristics and effects of the different available fault-clearing strategies are presented.

Kumar Biswajit Debnath

Heriot-Watt University,

United Kingdom

Gregorio D'Agostino,

Energy and Sustainable Economic

Development (ENEA), Italy

*Correspondence:

María José Pérez-Molina

mariajose.perez@ehu.eus

Specialty section:

This article was submitted to Sustainable Energy Systems and

Policies,

a section of the journal

Frontiers in Energy Research

Received: 09 December 2019

Accepted: 19 February 2020

Published: 28 February 2020

Citation:

Pérez-Molina MJ, Larruskain DM, Eguía López P and Buigues G (2020)

Challenges for Protection of Future

HVDC Grids. Front. Energy Res. 8:33.

doi: 10.3389/fenrg.2020.00033

\section{INTRODUCTION}

HVDC technology offers several advantages over the traditional AC technology, making it a promising and cheaper solution for future expansions of the grid or for new interconnections. Some of the advantages of HVDC systems are lower power losses and costs in long distance power links (Shang and Liang, 2014), lesser number of electrical conductors with smaller diameter and lower weight are needed to transmit the same amount of power (Johannesson et al., 2009), capability of transmitting power over long distances with underground or undersea cables (Le Blond et al., 2016) and capability of interconnecting asynchronous grids (Dambone Sessa et al., 2019). In addition, power flow controllability and flexibility of HVDC systems improves system stability during $\mathrm{AC}$ transients and allows efficient transmission of power from fluctuating and renewable power sources (Heyman et al., 2010). Hence, HVDC transmissions will have a significant part in the power grid transition to a more sustainable and renewable source based generation (Keshri and Tiwari, 2018). Grid connection of remote offshore wind power plants, bulk power transmissions and interconnections between nations are some examples of its application, which will contribute to the power grid of the future.

However, HVDC grids, similar to high voltage alternating current (HVAC) grids, are not failure proof. Fault between conductors and ground can happen. During fault conditions in an HVDC grid, two critical situations take place: the voltage drops sharply and the current increases rapidly 
to very high values, which is critical in grids with voltage source converters (VSC), the modern HVDC technology. Its power electronic devices can withstand only twice its rated current (Baran and Mahajan, 2007) and not the high fault-induced currents. If the fault is not cleared very fast, the VSC converter disconnects for self-protection. If this is the case, the entire HVDC grid can be lost with the corresponding large blackout. Hence, very fast and reliable protection systems are needed in order to avoid damages in the components (Azazi et al., 2014). This way, a fault must be detected, located and cleared in a very short range of time which can be defined in the order of $10 \mathrm{~ms}$ according to the literature (Descloux et al., 2012). Hence, fast protection algorithms and HVDC circuit breakers (CBs) have to be developed and an appropriate fault-clearing strategy has to be adopted in order to minimize the impact of fault condition in both the DC and the AC systems.

This paper is focused on the protection of HVDC grids and is organized in the following sections. A protection system must fulfill a series of requirements that are elaborated in section PROTECTION REQUIREMENTS. Then, the components of a protection system are presented in section PROTECTION SYSTEMS. Classification of measurement devices and protection algorithms are presented in subsections Measurement Devices and Protection Algorithms, respectively. Likewise, characteristics of the different types of CBs and fault-clearing strategies are described in subsections Circuit Breakers and FaultClearing Strategies. Finally, section Conclusions shows the main conclusions.

\section{PROTECTION REQUIREMENTS}

Fault conditions are dangerous not only for the system equipment but also for people. Therefore, they should be isolated and cleared as fast as possible (Farhadi and Mohammed, 2017). Hence, HVDC protection systems have to ensure safety and minimize fault impact and component stress. In order to do so, protection systems must operate satisfying some performance requirements (Leterme and van Hertem, 2016; Zhang et al., 2017):

- Accuracy: the protection system only operates when the fault condition is located inside its protection zone.

- Speed: fast operation in order to avoid damage on equipment and to minimize the fault impact on the system. This time covers the detection and identification times of the protection algorithm and the operation time of the CBs.

- Sensitivity: all relevant fault conditions must be detected.

- Selectivity: internal and external fault conditions must be properly differentiated and the isolated zone should be as small as possible.

- Recoverability: the system must reach a stable state after fault clearance.

\section{PROTECTION SYSTEMS}

The components of a protection system are described in this section. These components are mainly measurement devices, protection algorithms, circuit breakers and fault-clearing strategies. Measurement devices are in charge of adapting the signals needed by the relays to operate properly. Protection algorithms use these measurements in order to discriminate between normal and fault conditions. Circuit breakers isolate the faulty part of the system, interrupting the current. The adopted fault-clearing strategy determines the impact of a fault condition on the system.

\section{Measurement Devices}

Measurement devices adapt the voltage and current signals so protection relays can properly use them. They consist of a primary sensor, which adapts the amplitude signal, and a merging unit, which adjust the low amplitude signal to a suitable format for the relays (Blake and Rose, 2006). There are two types of measurement devices according to the measured signal: current measurement devices and voltage measurement devices.

\section{Voltage Measurement Devices}

The capacitive compensated resistive voltage divider is the most used primary sensor in DC applications. It consists of a resistor and a capacitor in parallel connection. Several RC groups connected in series allow the reduction of the primary voltage amplitude. This way, a high bandwidth of a few $\mathrm{MHz}$ can be achieved which will be limited by resonance effects due to stray inductances in the capacitive part (Minkner, 2005; Sperling and Schegner, 2013).

Optical voltage transformers can also be used to measure the DC voltage. They are based on the Pockels effect. The voltage and two polarized light waves are applied to an optical medium. The phase shift between these two waves at the end of the optical medium is equivalent to the voltage measurement (Bohnert et al., 2003).

\section{Current Measurement Devices}

There are different types of measurement devices which adapt the current signal. These are mainly zero-flux devices, fiber optic current sensors and hybrid electro-optical transducers.

A DC current transformer is a zero-flux device, which consists of two magnetic cores and three windings. Two of these windings measure the flux generated by the direct current and the remaining winding compensates the flux. Another zero-flux device is the Hall effect current transformer which consists of one magnetic core, one winding and Hall effect sensors. The sensors measure the flux in this case. The current flowing through the compensating winding is generated by an electronic circuit in zero flux devices. This current is provided as the voltage through a high burden resistor and it is equivalent to the current flowing to the conductor. Their bandwidth can be up to some hundreds of $\mathrm{kHz}$ (Appelo et al., 1977).

A fiber optic cable wrapped around the conductor constitutes the fiber optic current sensor, which is based on the Faraday effect; the speed difference between two polarized light waves is equivalent to the current measurement. This waves can travel through the cable in the same direction or different directions (Bohnert et al., 2007). Their bandwidth depends on the fiber optic cable and is in the range of $\mathrm{kHz}$ to $\mathrm{MHz}$ (Peelo et al., 2012). 
The combination of a Rogowski coil, a shunt and optical transmissions is a hybrid electro-optical transducer, which consists of an electrical sensor and optical transmissions to isolate the primary and secondary sides of the device. The high voltage measurements are converted to optical signals and transmitted to the low voltage side. In this case, the shunt is used to measure the current and the Rogowski coil increases the bandwidth to several MHz (Jenau and Testin, 2009).

\section{Protection Algorithms}

Fault conditions must be detected and located in a range of time shorter than $10 \mathrm{~ms}$ in HVDC systems, as it has been mentioned previously. Protection algorithms are in charge of locating and detecting fault conditions. They can be classified into localmeasurement-based or communication-based algorithms.

Local-measurement-based algorithms are very fast since they only use locally available measurements. However, these algorithms lack selectivity and they are sensitive to misdetection of external faults (Buigues et al., 2015; Torres-Olguin and Høidalen, 2015). Limiting inductors are placed at both ends of the protection zones in order to improve the selectivity of local-measurement-based algorithms since they damp signals originated outside the protection zone. In addition, these algorithms compare the measurements with threshold values as a way of discriminating between internal and external faults. This threshold value is generally selected through simulations ( $\mathrm{Li}$ et al., 2019) and taking into account that a higher value improves the selectivity but worsens the sensitivity of the algorithm. Some types of local-measurement-based algorithms are the overcurrent (Yang et al., 2010) and undervoltage algorithms (Leterme et al., 2015), which make use of the current and voltage magnitudes, respectively, and the rate-of-change-of-current (Geddada et al., 2018) and rate-of-change-of-voltage (Sneath and Rajapakse, 2015). An analysis of these algorithms is performed in a 4terminal symmetric monopole VSC-HVDC grid (Pérez Molina et al., 2019). Voltage-based algorithms are faster than currentbased ones due to the sharp voltage drop induced by a fault while the rate-of-rise-of-current is limited by the inductors. Moreover, derivative-based algorithms present a considerably faster detection time, especially than the overcurrent algorithm. Likewise, the rate-of-change-of-voltage is barely affected by the fault resistance and it presents the best performance under high impedance fault conditions due to the sharpness of the voltage drop.

Communication-based algorithms are based on exchanging data information between both ends of the protection zone (Jahn et al., 2017). Then, they are inherently selective (Marten et al., 2016), but they depend on the communication channel medium and the time delay imposed by it. This communication time delay can make the protection system not capable of meeting the requirement of speed ( $\mathrm{Li}$ and $\mathrm{Xu}, 2018$ ), even if the optical fiber is used, which presents a time delay of $1 \mathrm{~ms}$ per $200 \mathrm{~km}$ (Dallas and Booth, 2014). Consequently, the communication time delay is the most limiting parameter in the operation time of a communication-based algorithm (Pérez-Molina et al., 2019). Moreover, protection algorithms using a communication channel are not completely reliable since a problem in the communication channel will make the protection system nonoperative (Psaras et al., 2018). Hence, they are mostly used as backup protection systems (Naidoo and Ijumba, 2005), where the transmission distances are relatively short (Dallas and Booth, 2014) or to protect against high impedance fault conditions (Leterme et al., 2016) where the speed requirements is not so critical. Improved fault current limiting techniques may enable the use of communication-based algorithms as the main protection by limiting the rapid rise of the current and reducing the requirement of speed ( $\mathrm{Li}$ et al., 2019). Some examples are the differential current algorithm (Adamczyk et al., 2014), which compares the current flowing in and out of the protection zone, and the directional current (Kontos et al., 2015), which compares the direction of the current flow at both ends of the protection zone.

\section{Circuit Breakers}

HVDC circuit breakers have been commercially available for a short time at very high costs. Due to this, HVDC systems have been traditionally protected from DC faults using AC$\mathrm{CBs}$, located at the $\mathrm{AC}$ side, since they are a more economical and mature technology. However, they lack operation speed due to mechanical restrictions; their operation takes several cycles, tens of milliseconds (Leterme and van Hertem, 2015). Moreover, the shutdown of the converter, and in consequence, of all links connected to it (Alassi et al., 2019), is another challenging issue derived from the use of $\mathrm{AC}-\mathrm{CBs}$, which is very inconvenient and not appropriate for the case of multi-terminal HVDC grids (Candelaria and Park, 2011).

Meanwhile, DC protection devices present faster operation. In addition, they allow dividing the grid in protection zones. Hence, fault isolation is achieved while the healthy zones of the system continue operative (Shen et al., 2017). HVDC-CBs must offer short operating time and high current interruption capability (Descloux et al., 2013). In addition, they must produce a current zero in order to interrupt the current since it does not cross zero "naturally" as in AC systems (Bucher and Franck, 2016). Moreover, they must be capable of dissipating the energy stored in the system. These functions are achieved using different parallel branches. These branches usually are the main conduction branch, the commutation branch and the energy absorption branch (Franck, 2011). The current flows through the main conduction branch during normal operation, however, when a fault occurs, the current is forced to the commutation branch in order to be interrupted. The surge arresters located in the energy absorption branch dissipate the energy stored in the system.

Limiting inductors are used to limit the rate of rise of the current during fault conditions to the interrupting capability of the HVDC-CBs in addition to delimiting the borders of the protection zone and improving the selectivity of the algorithm. However, a larger size of the inductor results in the HVDC-CBs having to dissipate a larger amount of energy and also affects the stability of the system (Häfner and Jacobson, 2011).

The most common types of HVDC-CBs are mechanical, solidstate and hybrid circuit breakers. 
TABLE 1 | Comparison of HVDC circuit breaker technologies.

\begin{tabular}{llllll}
\hline $\begin{array}{l}\text { CB } \\
\text { Technology }\end{array}$ & Main branch & $\begin{array}{l}\text { Commutation } \\
\text { branch }\end{array}$ & $\begin{array}{c}\text { Operation } \\
\text { time }\end{array}$ & $\begin{array}{c}\text { On-state } \\
\text { losses }\end{array}$ & Costs \\
\hline Mechanical CB Mechanical & $\begin{array}{l}\text { LC resonant } \\
\text { breaker }\end{array}$ & $5-10 \mathrm{~ms}$ & Low & Low \\
Solid-state CB & $\begin{array}{l}\text { Power } \\
\text { electronic } \\
\text { devices }\end{array}$ & $\begin{array}{l}\text { Does not } \\
\text { present } \\
\text { commutation } \\
\text { branch }\end{array}$ & $\sim 1 \mathrm{~ms}$ & High & High \\
Hybrid CB & $\begin{array}{l}\text { Mechanical } \\
\text { switch and } \\
\text { power } \\
\text { electronic } \\
\text { devices }\end{array}$ & $\begin{array}{l}\text { Power electronic } \\
\text { breaker or } \\
\text { capacitor } \\
\text { snubber circuit }\end{array}$ & $2-5 \mathrm{~ms}$ & Medium & High \\
& & & & \\
& & & & \\
\end{tabular}

- Mechanical CBs: this type of CB presents a mechanical breaker in the main conduction branch, a LC resonant circuit in the commutation branch and the energy absorption branch. The resonant circuit can be passive; the resonance is triggered by the arc voltage generated by the mechanical breaker opening, or active; the resonance is triggered by a spark gap or a precharged capacitor and a semiconductor switch. In addition, they present the highest current interruption capability but are challenging in terms of speed (Eriksson et al., 2014); they have an operation time of 5-10 ms (Tahata et al., 2015).

- Solid-state CBs: they consist of a main conduction branch, an energy absorption branch and no commutation branch. The current is directly commutated from the main branch to the absorption branch. Due to this, they present great operation speed, in the order of $1 \mathrm{~ms}$, but high on-state losses since there is a large number of power electronic devices in the main conduction branch (Spahic et al., 2016).

- Hybrid CBs: they combine the advantages of the solid-state and mechanical CBs, i.e., fast operation $(2-5 \mathrm{~ms})$ and lower on-state losses (Davidson et al., 2015). They consist of a small number of power electronic devices and a mechanical switch in the main conduction branch. The components of the commutation branch depend on the model, e.g., a power electronic breaker (Häfner and Jacobson, 2011) or capacitor snubber circuits (Meyer et al., 2005). The power electronics in the main branch force the current into the commutation branch in order to enable the mechanical switch opening. Then, the current is commutated to the energy absorption branch, driving the line current to zero.

The presented CBs are compared in Table 1. Mechanical CBs present low costs and losses but slow operation. Conversely, solid-state CBs present fast operation but high costs and losses. Meanwhile, hybrid CBs improve the operation speed and losses of mechanical and solid-state CBs, respectively, but present high costs. Therefore, the hybrid CB is the most promising technology for HVDC systems (Li et al., 2019).

\section{Fault-Clearing Strategies}

The isolated part of the grid, after the detection of a fault condition, should be as small as possible in order to minimize the
TABLE 2 | Comparison of fault-clearing strategies.

\begin{tabular}{|c|c|c|c|}
\hline $\begin{array}{l}\text { Fault-clearing } \\
\text { strategy }\end{array}$ & Philosophy & Breaking device & $\begin{array}{l}\text { Fault-clearing } \\
\text { time }\end{array}$ \\
\hline Non-selective & $\begin{array}{l}\text { There is one } \\
\text { protection zone which } \\
\text { confines the entire } \\
\text { system }\end{array}$ & $\begin{array}{l}\text { AC-CBs or } \\
\text { fault-tolerant } \\
\text { converters and DC } \\
\text { switches }\end{array}$ & $\sim 60 \mathrm{~ms}$ \\
\hline Full-selective & $\begin{array}{l}\text { One delimited } \\
\text { protection zone per } \\
\text { each protected } \\
\text { element }\end{array}$ & HVDC-CBs & $<10 \mathrm{~ms}$ \\
\hline $\begin{array}{l}\text { Partially- } \\
\text { selective }\end{array}$ & $\begin{array}{l}\text { The system is } \\
\text { partitioned into smaller } \\
\text { zones which will be } \\
\text { treated independently }\end{array}$ & $\begin{array}{l}\text { HVDC-CBs or DC/DC } \\
\text { converters for system } \\
\text { partition. AC-CBs and } \\
\text { DC switches for fault } \\
\text { isolation. }\end{array}$ & $\begin{array}{l}\text { System partition: } \\
<10 \mathrm{~ms} \\
\text { Fault isolation: } \\
\sim 60 \mathrm{~ms}\end{array}$ \\
\hline
\end{tabular}

fault impact on the healthy zones of the HVDC grid and the AC grid and avoid damage due to stress on components. In addition, the shutdown of a big zone of the HVDC grid could affect the AC grid stability. Therefore, the impact of fault conditions on the system during the fault-clearing and post-fault recovery stages will vary according to the adopted fault-clearing strategy (Leterme et al., 2019). They are classified into non-selective, partially-selective or full-selective fault-clearing strategies.

- Non-selective strategy: the entire system is shut down when a fault condition is detected. AC-CBs are usually in charge of doing this. Then, the faulty part is isolated using DC switches located at both ends of each zone. Finally, the AC-CBs are reclosed in order to reenergise the system. Fault-tolerant converters are usually employed in this strategy (Psaras et al., 2018).

- Full-selective strategy: The system is divided into different protection zones in order to disconnect only the faulty zone. HVDC-CBs are located at both ends of every protection zone. This way, the impact of the fault condition is minimized and the healthy parts of the system continue operating. This is the most similar strategy to the traditional AC strategy.

- Partially-selective strategy: This strategy combines the previous ones. The system is partitioned into several protection zones interconnected by DC links. HVDC-CBs or DC/DC converters are placed on the interconnecting links in order to disconnect the faulty zone from the healthy zones after fault detection. There is no HVDC-CBs inside the protection zones. The faulty protection zone is shut down by AC-CBs after it has been disconnected from the rest of the grid. Then, the faulty part inside the protection zone is isolated using fast DC switches and the healthy parts are reenergised.

Table 2 presents a summary comparing the different strategies. The non-selective strategy shuts down the entire grid and presents the highest fault-clearing time due to the use of AC-CBs. Conversely, the full-selective strategy present the fastest operation due to the use of HVDC-CBs and only the affected zone is isolated. The partially-selective strategy 
partitions the system in a short time and then takes several of tens of milliseconds in isolating the affected part.

\section{CONCLUSIONS}

This paper is focused on the protection of HVDC grids. The importance of the speed requirement must be highlighted since it is critical in HVDC systems. Hence, local-measurementbased algorithms are mostly used since they present fast operation. However, they need limiting inductors to improve its selectivity. Meanwhile, communication-based algorithms are inherently selective but their operation speed is limited by the communication time delay imposed by the communication channel. On the other hand, HVDC-CBs must present high current interruption and energy dissipation capability. In addition, they must be able to produce a current zero in order to interrupt the fault current. Nowadays, the most common HVDCCBs are based on mechanical or hybrid technologies. Finally, the

\section{REFERENCES}

Adamczyk, A., Barker, C. D., and Ha, H. (2014). "Fault detection and branch identification for HVDC grids," in 12th IET International Conference on Developments in Power System Protection (DPSP 2014) (Copenhagen). doi: 10.1049/cp.2014.0013

Alassi, A., Bañales, S., Ellabban, O., Adam, G., and MacIver, C. (2019). HVDC transmission: technology review, market trends and future outlook. Renew. Sust. Energ. Rev. 112, 530-554. doi: 10.1016/j.rser.2019.04.062

Appelo, H. C., Groenenboom, M., and Lisser, J. (1977). The zero-flux DC current transformer a high precision bipolar wide-band measuring device. IEEE Trans. Nucl. Sci. 24, 1810-1811. doi: 10.1109/TNS.1977.4329095

Azazi, S., Sanaye-Pasand, M., Abedini, M., and Hasani, A. (2014). A traveling-wave-based methodology for wide-area fault location in multiterminal DC systems. IEEE Trans. Power Del. 29, 2552-2560. doi: 10.1109/TPWRD.2014.2323356

Baran, M. E., and Mahajan, N. R. (2007). Overcurrent protection on voltagesource-converter-based multiterminal DC distribution systems. IEEE Trans. Power Del. 22, 406-412. doi: 10.1109/TPWRD.2006.877086

Blake, Q., and Rose, Q. (2006). "Interfacing optical CTs and VTs to relays and meters," in 2005/2006 IEEE/PES Transmission and Distribution Conference and Exhibition (Dallas, TX). 21-24.

Bohnert, K., Brandle, H., Brunzel, M. G., Gabus, P., and Guggenbach, P. (2007). Highly accurate fiber-optic DC current sensor for the electrowinning industry. IEEE Trans. Ind. Appl. 43, 180-187. doi: 10.1109/TIA.2006.887311

Bohnert, K., Gabus, P., Braendle, H., and Khan, A. (2003). "Fiber-optic current and voltage sensors for high-voltage substations," in 16th International Conference on Optical Fiber Sensors (Nara).

Bucher, M. K., and Franck, C. M. (2016). Fault current interruption in multiterminal HVDC networks. IEEE Trans. Power Del. 31, 87-95. doi: 10.1109/TPWRD.2015.2448761

Buigues, G., Valverde, V., Zamora, I., Larruskain, D. M., Abarrategui, O., and Iturregi, A. (2015). "DC fault detection in VSC-based HVDC grids used for the integration of renewable energies," in 2015 International Conference on Clean Electrical Power (ICCEP) (Taormina: IEEE). doi: 10.1109/ICCEP.2015.7177591

Candelaria, J., and Park, J. (2011). "VSC-HVDC system protection: a review of current methods," in 2011 IEEE/PES Power Systems Conference and Exposition (Phoenix, AZ). doi: 10.1109/PSCE.2011.5772604

Dallas, I., and Booth, C. (2014). "Teleprotection in multi-terminal HVDC supergrids," in 12th IET International Conference on Developments in Power System Protection (DPSP 2014), (Copenhagen: IET). doi: 10.1049/cp.2014.0015

Dambone Sessa, S., Chiarelli, A., and Benato, R. (2019). Availability analysis of HVDC-VSC systems: a review. Energies 12:2703. doi: 10.3390/en12142703 different types of fault-clearing strategies that can be adopted into a protection system are indicated, being the full-selective strategy the most similar to the traditional AC system.

\section{AUTHOR CONTRIBUTIONS}

MP-M, DL, PE, and GB contributed conception and design of the study and wrote sections of the manuscript. MP wrote the first draft of the manuscript. All authors contributed to manuscript revision, read, and approved the submitted version.

\section{FUNDING}

This research was funded by the Spanish Ministry of Economy, Industry and Competitiveness (project ENE2016-79145-R AEI/FEDER, UE), the Basque Government (GISEL research group IT1191-19) and the UPV/EHU (GISEL research group 181/18).

Davidson, C. C., Whitehouse, R. S., Barker, C. D., Dupraz, J., and Grieshaber, W. (2015). "A new ultra-fast HVDC circuit breaker for meshed DC networks," in 11th IET International Conference on $A C$ and DC Power Transmission (Birmingham). doi: 10.1049/cp.201 5.0021

Descloux, J., Raison, B., and Curis, J. (2013). "Protection strategy for undersea MTDC grids," in 2013 IEEE Grenoble Conference (Grenoble). doi: 10.1109/PTC.2013.6652286

Descloux, J., Rault, P., Nguefeu, S., Curis, J., Guillaud, X., Colas, F., and Raison, B. (2012). "HVDC meshed grid: control and protection of a multi-terminal HVDC system," in CIGRÉ Session Paris (Paris: CIGRÉ).

Eriksson, T., Backman, M., and Halen, S. (2014). "A low loss mechanical hvdc breaker for HVDC grid applications,” in CIGRÉ 2014 (Paris).

Farhadi, M., and Mohammed, O. A. (2017). Protection of multi-terminal and distributed DC systems: design challenges and techniques. Electr. Pow. Syst. Res. 143, 715-727. doi: 10.1016/j.epsr.2016.10.038

Franck, C. M. (2011). HVDC circuit breakers: a review identifying future research needs. IEEE Trans. Power Del. 26, 998-1007. doi: 10.1109/TPWRD.2010.2095889

Geddada, N., Yeap, Y. M., and Ukil, A. (2018). Experimental validation of fault identification in VSC-based DC grid system. IEEE Trans. Ind. Electron. 65, 4799-4809. doi: 10.1109/TIE.2017.2767560

Häfner, J., and Jacobson, B. (2011). "Proactive hybrid HVDC breakers - a key innovation for reliable HVDC grids," in The Electric Power System of the Future - Integrating Supergrids and Microgrids International Symposium (Bologna).

Heyman, O., Sweden, A., and Weimers, L. (2010). HVDC-A Key Solution in Future Transmission Systems. Avaliable online at: https://www.researchgate. net/publication/229000667_HVDC-A_key_solution_in_future_transmission_ systems (accessed February 25, 2020).

Jahn, I., Johannesson, N., and Norrga, S. (2017). "Survey of methods for selective DC fault detection in MTDC grids," in 13th IET International Conference on AC and DC Power Transmission (ACDC 2017) (Manchester). doi: 10.1049/cp.2017.0041

Jenau, F., and Testin, G. (2009). "Modern instrument transformer technologies for UHV AC and HVDC networks," in IEC/CIGRE Symposium on Standards for UHV Transmission (New Delhi).

Johannesson, K., Gustafsson, A., Karlstrand, J., and Jeroense, M. (2009). "HVDC light cables for long distance grid connection," in European Offshore Wind Conference (Stockholm).

Keshri, J. P., and Tiwari, H. (2018). "Fault location methods in HVDC transmission system - a review," in Intelligent Computing Techniques for Smart Energy Systems (Rajasthan: Springer Singapore). 
Kontos, E., Pinto, R. T., Rodrigues, S., and Bauer, P. (2015). Impact of HVDC transmission system topology on multiterminal DC network faults. IEEE Trans. Power Del. 30, 844-852. doi: 10.1109/TPWRD.2014.23 57056

Le Blond, S., Bertho, R., Coury, D. V., and Vieira, J. C. M. (2016). Design of protection schemes for multi-terminal HVDC systems. Renew. Sust. Energ. Rev. 56, 965-974. doi: 10.1016/j.rser.2015.12.025

Leterme, W., Ahmed, N., Beerten, J., Ängquist, L., Hertem, D. V., and Norrga, S. (2015). "A new HVDC grid test system for HVDC grid dynamics and protection studies in EMT-type software," in 11th IET International Conference on $A C$ and DC Power Transmission (Birmingham: IET Digital Library). doi: $10.1049 /$ cp. 2015.0068

Leterme, W., Beerten, J., and Van Hertem, D. (2016). Nonunit protection of HVDC grids with inductive DC cable termination. IEEE Trans. Power Del. 31, 820-828. doi: 10.1109/TPWRD.2015.2422145

Leterme, W., Jahn, I., Ruffing, P., Sharifabadi, K., and van Hertem, D. (2019). Designing for high-voltage Dc grid protection: fault clearing strategies and protection algorithms. IEEE Power Energy Mag. 17, 73-81. doi: 10.1109/MPE.2019.2897188

Leterme, W., and van Hertem, D. (2015). "Classification of fault clearing strategies for HVDC grids," in CIGRÉ Lund Symposium (Lund).

Leterme, W., and van Hertem, D. (2016). "DC fault phenomena and DC grid protection. Chap. 17," in HVDC Grids : For Offshore and Supergrid of the Future, eds D. Van Herterm, O. Gomis-Bellmunt, and J. Liang ([Piscataway, NJ]; Hoboken, New Jersey: IEEE Press; Wiley), 345-370. doi: 10.1002/9781119115243.ch17

Li, B., He, J., Li, Y., and Li, B. (2019). A Review of the Protection for the Multi-Terminal VSC-HVDC Grid. Protect. Control Modern Power Sys. 4:21. doi: 10.1186/s41601-019-0136-2

Li, R., and Xu, L. (2018). Review of DC Fault Protection for HVDC Grids. WIREs Energy and Environ. 7:e278. doi: 10.1002/wene.278

Marten, A. K., Troitzsch, C., and Westermann, D. (2016). Non-telecommunication based dc line fault detection methodology for meshed HVDC grids. IET Gener. Transm. Dis.10, 4321-4239. doi: 10.1049/iet-gtd.2015.0700

Meyer, C., Kowal, M., and de Doncker, R. W. (2005). "Circuit breaker concepts for future high-power DC-applications," in Fourtieth IAS Annual Meeting. Conference Record of the 2005 Industry Applications Conference (2005) (Kowloon, Hong Kong).

Minkner, R. (2005). "Development trends in medium- and high voltage technologies for measuring systems, filters and bushings," in 2005 IEEE Russia Power Tech (St. Petersburg). doi: 10.1109/PTC.2005.4524818

Naidoo, D., and Ijumba, N. M. (2005). "HVDC line protection for the proposed future HVDC systems," in 2004 International Conference on Power System Technology (PowerCon 2004, Singapore).

Peelo, D., Rahmatian, F., Nagpal, M., and Sydor, D. (2012). "Real-time monitoring and capture of power system transients," in CIGRÉ 2012 (Paris).

Pérez Molina, M. J., Larruskain, D. M., Eguía López, P., and Etxegarai, A. (2019). Analysis of local measurement-based algorithms for fault detection in a multi-terminal HVDC grid. Energies 12. doi: 10.3390/en122 44808
Pérez-Molina, M. J., Larruskain, D. M., Eguia Lopez, P., Abarrategi, O., and SantosMugica, M. (2019). "A comparison of non-unit and unit protection algorithms for HVDC grids," in AEIT HVDC International Conference 2019 (Florence). doi: 10.1109/AEIT-HVDC.2019.8740430

Psaras, V., Emhemed, A., Adam, G., and Burt, G. M. (2018). "Review and evaluation of the state of the art of DC fault detection for HVDC grids," in 2018 53rd International Universities Power Engineering Conference (UPEC) (Glasgow). doi: 10.1109/UPEC.2018.8541961

Shang, L., and Liang, W. (2014). The review of high voltage DC transmission lines fault location. Int. J. Comp. Consumer and Control (IJ3C). 3, 21-28. Available online at: http://ij3c.ncuteecs.org/volume/3-4.php (accessed on February 26, 2020).

Shen, L., Tang, Q., Li, T., Wang, Y., and Song, F. (2017). "A review on VSC-HVDC reliability modeling and evaluation techniques," in 2017 2nd Asia Conference on Power and Electrical Engineering (ACPEE 2017), (Shanghai).

Sneath, J., and Rajapakse, A. D. (2015). "DC fault protection of a nine-terminal mmc HVDC grid," in 11th IET International Conference on AC and DC Power Transmission, (Birmingham). doi: 10.1049/cp.2015.0082

Spahic, E., Ergin, D., Schettler, F., Dorn, J., and Petino, C. (2016). "A Closer Look at Protection Concepts for DC Systems," in CIGRÉ 2016, (Paris).

Sperling, E., and Schegner, P. (2013). "A possibility to measure power quality with RC-divider," in 22nd International Conference and Exhibition on Electricity Distribution (CIRED 2013) (Stockholm). doi: 10.1049/cp.2013.0602

Tahata, K., Oukaili, S. E., Kamei, K., Yoshida, D., Kono, Y., Yamamoto, R., and Ito, H. (2015). "HVDC circuit breakers for HVDC grid applications," in 11th IET International Conference on AC and DC Power Transmission (Birmingham). doi: $10.1049 / \mathrm{cp} .2015 .0018$

Torres-Olguin, R. E., and Høidalen, H. K. (2015). "Inverse time overcurrent protection scheme for fault location in multi-terminal HVDC," in 2015 IEEE Eindhoven PowerTech (Eindhoven: IEEE). doi: 10.1109/PTC.2015.7232673

Yang, J., Fletcher, J. E., O’Reilly, J., Adam, G. P., and Fan, S. (2010). "Protection scheme design for meshed VSC-HVDC transmission systems of large-scale wind farms," in 9th IET International Conference on AC and DC Power Transmission (ACDC 2010) (London: IET). doi: 10.1049/cp.2010.0996

Zhang, L., Zou, Y., Yu, J., Qin, J., Vittal, V., Karady, G. G., Shi, D., and Wang, Z. (2017). Modeling, control, and protection of modular multilevel converterbased multi-terminal HVDC systems: a review. CSEE J. Power Energy Syst. 3 , 340-352. doi: 10.17775/CSEEJPES.2017.00440

Conflict of Interest: The authors declare that the research was conducted in the absence of any commercial or financial relationships that could be construed as a potential conflict of interest.

Copyright (๑ 2020 Pérez-Molina, Larruskain, Eguía López and Buigues. This is an open-access article distributed under the terms of the Creative Commons Attribution License (CC BY). The use, distribution or reproduction in other forums is permitted, provided the original author(s) and the copyright owner(s) are credited and that the original publication in this journal is cited, in accordance with accepted academic practice. No use, distribution or reproduction is permitted which does not comply with these terms. 